SANTOS, A.L.Q. et al. Avaliação do comportamento de touros no ambiente de rodeio.

PUBVET, Londrina, V. 5, N. 26, Ed. 173, Art. 1170, 2011.

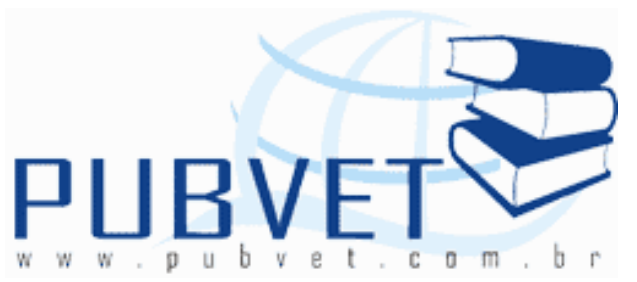

PUBVET, Publicações em Medicina Veterinária e Zootecnia.

\title{
Avaliação do comportamento de touros no ambiente de rodeio
}

André Luiz Quagliatto Santos ${ }^{1}$; Thaís Carneiro Santos Rodrigues ${ }^{2}$; Natália Siqueira D'Aparecida2; Omar Teodoro Silva Júnior3; Mariana Rodrigues Moreira ${ }^{4}$; Patrícia Massuda ${ }^{4}$; Flávio Machado de Moraes ${ }^{3}$

1. Professor Titular da Faculdade de Medicina Veterinária, Universidade Federal de Uberlândia-UFU 2. Graduandos da Faculdade de Medicina Veterinária, Universidade Federal de Uberlândia-UFU 3. Mestrando da Faculdade de Medicina Veterinária, Universidade Federal de Uberlândia-UFU 4. Médicas Veterinárias

\section{Resumo}

O rodeio, prática muito difundida no Brasil e conhecida em todo o mundo, ocasiona uma maior interação do homem com o animal, gerando neste último diversas alterações comportamentais. Esta pesquisa teve o objetivo de verificar as variações de comportamento decorrentes de rodeio de touros. Foram observadas 228 montarias de touros em rodeios nas cidades de Ibiá, Monte Alegre de Minas, Uberaba e Uberlândia (MG). O rodeio foi dividido em fases: brete, trabalho e retorno. Os animais foram observados seguindo três parâmetros de comportamento: dócil, normal e agressivo, sendo avaliados nas três fases do rodeio. Com a análise estatística (teste de $\mathrm{z}$ ) verificou-se diferença estatística significativa nos dados avaliados. Foi concluído que os touros de rodeio alteram o seu comportamento entre as fases de brete e 
SANTOS, A.L.Q. et al. Avaliação do comportamento de touros no ambiente de rodeio. PUBVET, Londrina, V. 5, N. 26, Ed. 173, Art. 1170, 2011.

trabalho aumentando a agressividade e entre as fases de trabalho e retorno, os touros mantêm o comportamento ou diminuem a agressividade.

Palavras-chave: Comportamento, Rodeio, Touros

\title{
Performance evaluation of bulls in the environment of rodeo
}

\begin{abstract}
The rodeo is a common practice in Brazil and abroad. This activity makes the relationship between man and animal greater, and it causes behavior variations. This study aimed to assess the variations in behavior of bulls in rodeo. 228 bulls in rodeos were observed in the cities of Ibiá, Monte Alegre de Minas, Uberaba and Uberlândia (MG). The rodeo was divided into three phases: brete, work. The animals were observed following three parameters of behavior: gentle, normal and aggressive. The statistical analysis ( $z$ test) showed statistically significant differences in the evaluated numbers. We conclude that the rodeo bulls change their behavior between the phases of work brete and increased aggression and between phases of work and return, the Bulls remain the behavior or decrease aggression.
\end{abstract}

Keywords: Behavior, Bulls, Rodeo

\section{INTRODUÇÃO}

O rodeio é montaria em touros e consiste em permanecer oito segundos sobre o animal, segurando com apenas uma das mãos, apoiando-se em uma corda que envolve o tórax do animal, denominada corda americana (SERRA, 2000). Utiliza-se também o sedém, corda ou trança que serve para estimular os pulos do touro, sendo amarrada na região inguinal do animal. De acordo com a Lei Federal n 10519 de Julho de 2002, é proibido utilizar esporas com rosetas pontiagudas ou qualquer artifício que possa provocar injúria nos touros.

Antes da montaria os animais ficam nos bretes, onde são equipados, e os peões se posicionam no touro aguardando a abertura do portão do brete para 
SANTOS, A.L.Q. et al. Avaliação do comportamento de touros no ambiente de rodeio. PUBVET, Londrina, V. 5, N. 26, Ed. 173, Art. 1170, 2011.

dar início à montaria. A montaria ocorre na arena, uma pista de areia fofa, com medidas que variam entre 50 e 60 metros de comprimento por 40 a $50 \mathrm{~m}$ de largura. Após a montaria os touros retornam aos bretes, e são colocados em piquetes ou currais (SERRA, 2000).

Este trabalho pretende avaliar o estresse e as variações comportamentais de touros de rodeio, através da análise e coleta de dados, visando o bem estar destes animais.

\section{MATERIAL E MÉTODOS}

A pesquisa foi realizada no ano de 2005, em rodeios nas cidades de Ibiá, Monte Alegre de Minas, Uberaba e Uberlândia, todas no estado de Minas Gerais. Foram observadas 228 montarias em touros de rodeio. Durante as montarias, anotou-se em planilhas o nome do touro, nome do peão, comportamento do touro no brete, na arena e no retorno, e demais observações necessárias. Todas as coletas de dados foram realizadas por apenas uma pessoa, de forma a manter o mesmo padrão de avaliações, já que os parâmetros avaliados são de caráter subjetivo.

As fases do rodeio foram definidas de acordo com a pesquisa realizada por Tormen (1999). A fase de brete foi considerada como a preparação do animal no brete, em que se dispunham os equipamentos (sedém e corda americana) no touro e posicionamento do peão no touro e do touro propriamente dito para iniciar a montaria. A fase de trabalho compreende todo o tempo de montaria do peão no touro e os instantes que sucedem a queda do peão ainda na arena. A fase de retorno compreende a volta do animal ao piquete, no fundo dos bretes e a retirada dos equipamentos utilizados na montaria.

Montou-se então um protocolo de pesquisa no qual o comportamento dos touros na fase de brete pudesse ser estatisticamente comparado ao seu comportamento na fase de trabalho, e o comportamento dos animais nesta fase pudesse ser comparado estatisticamente com o comportamento destes na 
SANTOS, A.L.Q. et al. Avaliação do comportamento de touros no ambiente de rodeio. PUBVET, Londrina, V. 5, N. 26, Ed. 173, Art. 1170, 2011.

fase de retorno. Foram avaliados três tipos de comportamento em cada fase do rodeio: dócil, normal e agressivo.

Dentro do brete, o comportamento dócil foi considerado quando os touros aparentavam-se indiferentes à presença do peão, sem fazer nenhum movimento brusco ou violento, permitindo a disposição dos equipamentos sem grandes dificuldades. O comportamento normal foi considerado quando os animais demonstraram reação à presença do peão e/ou ao aperto da corda americana e/ou ao colocar o sedém, porém não apresentaram dificuldade durante o posicionamento dos peões. No comportamento agressivo os touros mostraram-se inquietos e agitados com a presença dos peões ou com o apertar da corda americana, manuseio do sedém ou no encostar das esporas do peão, reagindo de maneira brusca e violenta, tentando saltar, deitar ou virar no brete, dificultando o posicionamento dos peões.

Dentro da arena, durante a montaria e imediatamente após a montaria, o comportamento foi avaliado como dócil nos animais que pararam de pular e permaneceram parados ou trotaram lentamente em alguma direção, geralmente em sentido contrário a localização dos bretes. No comportamento normal, avaliaram-se os touros que pularam sem proporcionar grandes dificuldades para a montaria dos peões e continuaram pulando após a queda do peão, porém por pouco tempo e sem tentativa de agressão a qualquer indivíduo presente na arena. O comportamento foi considerado agressivo em touros que proporcionaram grande dificuldade para a montaria dos peões na arena e procuraram chifrar, cabecear ou escoicear qualquer um dos presentes na arena logo após a queda do peão.

Após a montaria, no retorno, os animais foram considerados dóceis quando voltaram tranqüilamente ao piquete e permitiram que retirassem os equipamentos sem qualquer movimento de agressão às pessoas que estivessem próximas. No comportamento normal os touros voltaram ao piquete tranqüilamente, ou mostraram pequena resistência em voltar, ou não permitiram a retirada rápida dos equipamentos. Por fim, foi considerado comportamento agressivo quando os touros mesmo voltando normalmente ao 
SANTOS, A.L.Q. et al. Avaliação do comportamento de touros no ambiente de rodeio. PUBVET, Londrina, V. 5, N. 26, Ed. 173, Art. 1170, 2011.

piquete (fundo dos bretes) demonstraram grande resistência à retirada dos equipamentos, além de tentarem agredir pessoas que se encontravam próximas ao local.

A análise dos resultados ocorreu tomando-se a percentagem dos comportamentos dos animais no brete, na arena e no retorno, além da análise percentual na mudança de comportamento do animal do brete para a arena e da arena para o retorno, verificando também a porcentagem de touros que aumentaram ou diminuíram a agressividade entre as fases do rodeio. Foi analisada também a mudança de comportamento no rodeio como um todo. Para o cálculo estatístico utilizou-se o teste z (Teste de hipótese para diferença de proporções), com nível de significância de 0,05 (RODRIGUES, 1986).

\section{RESULTADOS}

O resultado das observações realizadas nos rodeios está representado na Tabela 1. Nas demais tabelas (Tabela 2 a Tabela 6) estão representados os resultados obtidos através de analises estatísticas dos dados coletados.

Tabela 1- Avaliação do comportamento dos touros relacionado às fases dos rodeios, realizado nas cidades de Ibiá, Monte Alegre de Minas, Uberaba e Uberlândia (MG), em 2005.

\begin{tabular}{l|c|c|c|c|c|c}
\hline \multirow{2}{*}{ COMPORTAMENTOS } & \multicolumn{6}{|c}{ FASES DO RODEIO } \\
\cline { 2 - 7 } & \multicolumn{2}{|c|}{ BRETE } & \multicolumn{2}{c}{ TRABALHO } & \multicolumn{2}{c}{ RETORNO } \\
\cline { 2 - 7 } & $N^{\circ}$ TOUROS & $\%$ & $N^{\circ}$ TOUROS & $\%$ & $N^{\circ}$ TOUROS & $\%$ \\
\hline Dócil & 160 & 70,2 & 4 & 1,8 & 110 & 48,3 \\
Normal & 55 & 24,1 & 220 & 96,4 & 105 & 46,0 \\
Agressivo & 13 & 5,7 & 4 & 1,8 & 13 & 5,7 \\
\hline
\end{tabular}


SANTOS, A.L.Q. et al. Avaliação do comportamento de touros no ambiente de rodeio. PUBVET, Londrina, V. 5, N. 26, Ed. 173, Art. 1170, 2011.

Tabela 2- Proporções e valores absolutos de touros de acordo com a comparação e a variável utilizada, obtidos em observações de rodeios realizado nas cidades de Ibiá, Monte Alegre de Minas, Uberaba e Uberlândia (MG), em 2005.

\begin{tabular}{|c|c|c|c|c|c|}
\hline COMPARAÇÃO & VARIÁVEL & $\mathrm{p} 1$ & p2 & $\mathrm{n} 1$ & $\mathrm{n} 2$ \\
\hline Brete $\mathrm{X}$ trabalho & Dócil & 0.70 & 0.02 & 160 & 4 \\
\hline Brete $X$ trabalho & Normal & 0.24 & 0.96 & 55 & 220 \\
\hline Brete $X$ trabalho & Agressivo & 0.06 & 0.02 & 13 & 4 \\
\hline Trabalho $X$ retorno & Dócil & 0.02 & 0.48 & 4 & 110 \\
\hline Trabalho $\mathrm{X}$ retorno & Normal & 0.96 & 0.46 & 220 & 105 \\
\hline Trabalho X retorno & Agressivo & 0.02 & 0.06 & 4 & 13 \\
\hline $\mathrm{d} X \mathrm{n}+\mathrm{a}$ & Brete & 0.70 & 0.29 & 160 & 68 \\
\hline $\mathrm{n} X \mathrm{~d}+\mathrm{a}$ & Brete & 0.24 & 0.76 & 55 & 173 \\
\hline$a x d+n$ & Brete & 0.06 & 0.94 & 13 & 215 \\
\hline$d x n+a$ & Trabalho & 0.02 & 0.98 & 4 & 224 \\
\hline$n \times d+a$ & Trabalho & 0.96 & 0.04 & 220 & 8 \\
\hline$a x d+n$ & Trabalho & 0.02 & 0.98 & 4 & 224 \\
\hline $\mathrm{d} X \mathrm{n}+\mathrm{a}$ & Retorno & 0.48 & 0.52 & 110 & 118 \\
\hline$n \times d+a$ & Retorno & 0.46 & 0.54 & 123 & 105 \\
\hline$a x d+n$ & Retorno & 0.06 & 0.94 & 13 & 215 \\
\hline
\end{tabular}

Nota: $\mathrm{d} X \mathrm{n}+\mathrm{a}$ : dócil $\mathrm{X}$ normal + agressivo; $\mathrm{n} X \mathrm{~d}+\mathrm{a}$ : normal $\mathrm{X}$ dócil + agressivo; a $X \mathrm{~d}+\mathrm{n}$ : agressivo $\mathrm{X}$ dócil + normal. 
SANTOS, A.L.Q. et al. Avaliação do comportamento de touros no ambiente de rodeio. PUBVET, Londrina, V. 5, N. 26, Ed. 173, Art. 1170, 2011.

Tabela 3- Valores de $z$ e das probabilidades a eles associadas, obtidas quando da aplicação do teste $\mathrm{z}$ aos dados relativos às proporções encontradas nas observações efetuadas.

\begin{tabular}{|c|c|c|c|}
\hline $\begin{array}{l}\text { COMPARAÇÃO } \\
\text { ANALISADA }\end{array}$ & $\begin{array}{c}\text { COMPORTAMENTOS/ } \\
\text { FASES }\end{array}$ & $\begin{array}{c}\text { VALORES } \\
\text { DE Z }\end{array}$ & PROBABILIDADES \\
\hline Brete $x$ trabalho & Dócil & 8,6273 & $0,0000 *$ \\
\hline Brete $x$ trabalho & Normal & $-12,1861$ & $0,0000 *$ \\
\hline Brete $x$ trabalho & Agressivo & 0,3244 & 0,7457 \\
\hline Trabalho $\mathrm{x}$ retorno & Dócil & $-5,4328$ & $0,0000 *$ \\
\hline Trabalho $\mathrm{x}$ retorno & Normal & 9,9204 & $0,0000 *$ \\
\hline Trabalho $\mathrm{x}$ retorno & Agressivo & $-0,4162$ & 0,6773 \\
\hline $\begin{array}{c}\text { Dócil } x \text { normal + } \\
\text { agressivo }\end{array}$ & Brete & 6,2232 & $0,0000 *$ \\
\hline $\begin{array}{c}\text { Normal x dócil }+ \\
\text { agressivo }\end{array}$ & Brete & $-7,8655$ & $0,0000 *$ \\
\hline $\begin{array}{c}\text { Agressivo } x \text { dócil }+ \\
\text { normal }\end{array}$ & Brete & $-12,9738$ & $0,0000 *$ \\
\hline $\begin{array}{c}\text { Dócil } x \text { normal + } \\
\text { agressivo }\end{array}$ & Trabalho & $-13,5935$ & $0,0000 *$ \\
\hline $\begin{array}{c}\text { Normal } x \text { dócil }+ \\
\text { agressivo }\end{array}$ & Trabalho & 13,0440 & $0,0000 *$ \\
\hline $\begin{array}{c}\text { Agressivo } \mathrm{x} \text { dócil }+ \\
\text { normal }\end{array}$ & Trabalho & $-13,5935$ & $0,0000 *$ \\
\hline $\begin{array}{c}\text { Dócil x normal + } \\
\text { agressivo }\end{array}$ & Retorno & $-0,6041$ & 0,5458 \\
\hline $\begin{array}{l}\text { Normal x dócil }+ \\
\text { agressivo }\end{array}$ & Retorno & $-1,2081$ & 0,2270 \\
\hline $\begin{array}{c}\text { Agressivo } x \text { dócil }+ \\
\text { normal }\end{array}$ & Retorno & $-12,9738$ & $0,0000 *$ \\
\hline
\end{tabular}

Nota: $(*) \mathrm{p}<0,05$; o termo agress refere-se ao comportamento agressivo. 
SANTOS, A.L.Q. et al. Avaliação do comportamento de touros no ambiente de rodeio. PUBVET, Londrina, V. 5, N. 26, Ed. 173, Art. 1170, 2011.

De acordo com os resultados demonstrados na Tabela 3, observa-se que foram encontradas diferenças significantes entre as variáveis:

- brete $\mathrm{x}$ trabalho e comportamento dócil, sendo que os valores mais elevados foram os relativos ao brete;

- brete $\mathrm{x}$ trabalho e comportamento normal, sendo que os valores mais elevados foram os relativos ao trabalho;

- trabalho x retorno e comportamento dócil, sendo que os valores mais elevados foram os relativos ao retorno;

- trabalho x retorno e comportamento normal, sendo que os valores mais elevados foram os relativos ao trabalho;

- dócil x normal + agressivo e brete, sendo que os valores mais elevados foram os relativos ao dócil;

- normal x dócil + agressivo e brete, sendo que os valores mais elevados foram os relativos ao dócil + agressivo;

- agressivo x dócil + normal e brete, sendo que os valores mais elevados foram os relativos ao dócil + normal;

- dócil x normal + agressivo e trabalho, sendo que os valores mais elevados foram os relativos ao normal + agressivo;

- normal x dócil + agressivo e trabalho, sendo que os valores mais elevados foram os relativos ao normal;

- agressivo x dócil + normal e trabalho, sendo que os valores mais elevados foram os relativos ao dócil + normal;

- agressivo x dócil + normal e retorno, sendo que os valores mais elevados foram os relativos ao dócil + normal. 
SANTOS, A.L.Q. et al. Avaliação do comportamento de touros no ambiente de rodeio. PUBVET, Londrina, V. 5, N. 26, Ed. 173, Art. 1170, 2011.

Tabela 4- Mudança do comportamento de touros entre fases, nos rodeios realizados nas cidades de Ibiá, Monte Alegre de Minas, Uberaba e Uberlândia (MG), em 2005.

\begin{tabular}{l|c|c|c|c}
\hline \multirow{2}{*}{ COMPORTAMENTOS } & \multicolumn{4}{|c}{ FASES DO RODEIO } \\
\cline { 2 - 5 } & \multicolumn{2}{|c|}{ BRETE } & \multicolumn{2}{c}{ TRABALHO } \\
\cline { 2 - 5 } & No TOUROS & $\%$ & $\begin{array}{c}\mathrm{N}^{\circ} \\
\text { TOUROS }\end{array}$ & $\%$ \\
\hline Dócil / Dócil & 4 & 1,8 & 3 & 1,3 \\
Dócil / Normal & 154 & 67,5 & 1 & 0,4 \\
Dócil / Agressivo & 2 & 0,9 & $\mathrm{z}$ & $\mathrm{z}$ \\
Normal / Dócil & $\mathrm{z}$ & $\mathrm{z}$ & 107 & 47,0 \\
Normal / Normal & 54 & 23,7 & 101 & 44,3 \\
Normal / Agressivo & 1 & 0,4 & 12 & 5,3 \\
Agressivo / Dócil & $\mathrm{z}$ & $\mathrm{z}$ & $\mathrm{z}$ & $\mathrm{z}$ \\
Agressivo / Normal & 12 & 5,3 & 3 & 1,3 \\
Agressivo / & 1 & 0,4 & 1 & 0,4 \\
Agressivo & & & & \\
\hline
\end{tabular}

Assim, temos que na fase de brete $70,2 \%$ dos animais demonstraram-se dóceis, $24,1 \%$ normais e $5,7 \%$ agressivos. Na fase de trabalho ou durante a montaria $1,8 \%$ dos animais demonstraram-se dóceis, $96,4 \%$ normais e $1,8 \%$ agressivo. Já na fase de retorno $48,3 \%$ dos touros demonstraram-se dóceis, $46,0 \%$ normais e $5,7 \%$ agressivos. Os dados relacionados ao brete se aproximam aos de Tormem (1999).

Com a análise estatística confirmou-se que na comparação entre brete e trabalho, em relação ao comportamento dócil, assim como na comparação entre dócil + normal e agressivo em relação ao brete, as porcentagens de comportamento dócil ou dócil + normal foram maiores no brete. Isso ocorreu devido ao animal estar acostumado a passar no brete, receber treinamento e 
SANTOS, A.L.Q. et al. Avaliação do comportamento de touros no ambiente de rodeio. PUBVET, Londrina, V. 5, N. 26, Ed. 173, Art. 1170, 2011.

manejo rotineiro, além da maioria dos touros serem animais que já competem em campeonatos há algum tempo, concordando com os relatos de Glaser (2003), em relação à adaptação do animal ao seu sistema de criação, e de Rosa e Costa (2005), quanto ao uso do manejo racional.

Tabela 5- Alteração do comportamento dos touros de rodeio de acordo com aumento ou diminuição da agressividade entre fases, evento realizado nas cidades de Ibiá, Monte Alegre de Minas, Uberaba e Uberlândia (MG), em 2005.

\begin{tabular}{c|c|c|c|c}
\hline \multirow{2}{*}{$\begin{array}{c}\text { ALTERAÇÃO } \\
\text { DO }\end{array}$} & \multicolumn{4}{|c}{ FASES DO RODEIO } \\
\cline { 2 - 5 } COMPORTAMENTO & \multicolumn{2}{|c|}{ BRETE/TRABALHO } & \multicolumn{2}{|c}{ TRABALHO/RETORNO } \\
\cline { 2 - 5 } & $\begin{array}{c}\mathrm{N}^{\circ} \\
\text { TOUROS }\end{array}$ & $\%$ & $\mathrm{~N}^{\circ}$ TOUROS & $\%$ \\
\hline $\begin{array}{c}\text { Aumenta } \\
\text { agressividade } \\
\text { Diminui } \\
\begin{array}{c}\text { agressividade } \\
\text { Sem alteração }\end{array}\end{array}$ & 157 & 68,8 & 13 & 5,7 \\
\hline
\end{tabular}

Tabela 6- Alteração do comportamento dos touros de rodeio no evento com um todo, realizado nas cidades de Ibiá, Monte Alegre de Minas, Uberaba e Uberlândia (MG), em 2005.

\begin{tabular}{l|c|c}
\hline \multicolumn{1}{c|}{$\begin{array}{c}\text { ALTERAÇÃO DO } \\
\text { COMPORTAMENTO }\end{array}$} & $\begin{array}{c}\text { NÚMERO DE } \\
\text { TOUROS }\end{array}$ & $\%$ \\
\hline Com alteração & 199 & 87,3 \\
Sem alteração & 29 & 12,7 \\
\hline
\end{tabular}

Quanto à comparação entre brete e trabalho, em relação ao comportamento normal e entre trabalho e retorno, em relação ao comportamento normal, 
SANTOS, A.L.Q. et al. Avaliação do comportamento de touros no ambiente de rodeio. PUBVET, Londrina, V. 5, N. 26, Ed. 173, Art. 1170, 2011.

encontrou-se porcentagem de comportamento normal mais elevado durante a montaria (trabalho) devido ao uso de esporas do peão para se apoiar no touro, animal se sentir incomodado com o sedém e à presença do peão no seu lombo, bem como a corda americana apertada e o barulho.

Observou-se maior porcentagem de comportamento dócil no retorno devido perda dos estímulos promovidos pelas esporas do peão, ausência do peão no lombo do touro, afrouxamento do sedém e da corda americana e diminuição de barulho. Concordando com as informações de Prada et al. (2002), sobre o uso de estímulos para que o animal se apresente na arena.

Em relação ao brete, os parâmetros dócil + agressivo e dócil + normal obtiveram porcentagens maiores, sendo o número de animais dóceis maior que o de normais e agressivos. Para a comparação entre dócil e normal + agressivo; normal e dócil + agressivo; agressivo e dócil + normal, todas em relação ao trabalho, o número de animais com temperamento normal foi maior, predominando a variável relacionada a comportamento normal no trabalho. Na comparação entre agressivo e dócil + normal, em relação ao retorno o número de animais agressivos foi muito pequeno quando comparado com as outras variáveis.

Analisando as porcentagens, em relação à mudança de comportamento de touros, entre fases, observou-se que, entre as fases de brete e trabalho, $67,5 \%$ dos animais mudaram de comportamento dócil para normal, entre as fases de trabalho e retorno, $47,0 \%$ dos animais passaram de normal para dócil e $44,3 \%$ permaneceram normais entre estas fases. Logo, entre as fases de brete e trabalho $68,8 \%$ dos touros aumentaram a agressividade, entre as fases de trabalho e retorno, 48,3\% diminuíram a agressividade e 46,0\% não demonstraram alteração de comportamento.

Em relação à diminuição ou aumento da agressividade entre as fases de brete e trabalho, observou-se que $5,3 \%$ dos animais diminuíram a agressividade, sendo que a porcentagem se aproxima a de Tormem (1999); porém $68,8 \%$ dos animais aumentaram a agressividade e $25,9 \%$ não 
SANTOS, A.L.Q. et al. Avaliação do comportamento de touros no ambiente de rodeio. PUBVET, Londrina, V. 5, N. 26, Ed. 173, Art. 1170, 2011.

alteraram o comportamento, valores que diferem aos observados por Tormem (1999).

Em relação ao rodeio como um todo, $87,3 \%$ dos animais alteraram o comportamento de alguma forma, diminuindo ou aumentando a agressividade.

\section{CONCLUSÕES}

Concluiu-se que os touros de rodeio alteram o seu comportamento entre as fases de brete e trabalho, com aumento da agressividade. Entre as fases de trabalho e retorno, os touros mantêm o comportamento ou sofrem um decréscimo na agressividade, em proporções equivalentes. Em todo o rodeio a maioria dos touros sofre alterações de comportamento.

\section{REFERÊNCIAS BIBLIOGRÁFICAS}

Variances and covariances between productive and adaptive traits and temperament in a composite breed of tropical beef cattle. Livestock Production Science, [S.I.], v. 70, n. 3, p. 213-233, aug. 2001.

MAFFEI, W. E.; FACURY, R. do N. Avaliação preliminar da reatividade dos animais da raça Nelore do Quinto Programa Touros do Futuro, medida em ambiente de contenção móvel. In: CONGRESSO BRASILEIRO DAS RAÇAS ZEBUÍNAS, 6., 2005, Uberaba. Resumos Uberaba: [s.n.], 2005. p.315-318.

MAFFEI, W. E.; BERGMANN, J. A. G.; BARBOSA, M. P. Reat-teste - um novo método para quantificar o temperamento bovino. In: CONGRESSO BRASILEIRO DAS RAÇAS ZEBUINAS, 6., 2005, Uberaba. Resumos Uberaba: [s.n.], 2005. p.318-321.

MOURÃO, G. B., BERGMANN, J. A., MADALENA, F. E., FERREIRA, M. B. Diferenças genéticas e estimação de coeficientes de herdabilidade para características morfológicas em fêmeas zebus e F1 Holandês-Zebu. Revista Brasileira de Zootecnia,Viçosa, v. 28, n. 1, p. 44-54, jan./fev. 1999.

PARANHOS DA COSTA, M. J. R. Qualidade total e racionalização do manejo de bovinos In: SEMINÁRIO ANUAL DO PROGRAMA DE MELHORAMENTO GENÉTICO DO REBANHO NELORE, 10., 2001, Ribeirão Preto. Anais Ribeirão Preto-SP: Associação Nacional de Criadores e Pesquisadores, 2001. 1 CD-ROM.

PRADA, I. L. S. A alma dos animais. Campos do Jordão: Mantiqueira, 1997. 63 p.

RODEIO. Hippus, São Paulo: Três, n. 191, 34 p., 1995. Edição especial.

RODRIGUES, P. C. Teste de Hipóteses. In: Bioestatística. Niterói: Universitária, 1986. cap. 12, p. 71-79. 
ROSA, M. S. da.; COSTA, M. J. R. P. da. O reflexo da interação amigável entre humaos e bovinos no bem-estar na fazenda. In: CONGRESSO BRASILEIRO DAS RAÇAS ZEBUÍNAS, 6., 2005, Uberaba. Anais... Uberaba: [s.n.], 2005. p.71-79.

SERRA, R. Rodeio: uma paixão! Rio de Janeiro: Gryphus, 2000. 228p.

TANNENBAUM, J. Veterinary ethics: animal welfare, client relations, competition and collegiality. 2. ed. St. Louis: Mosby-year Book, 1995. 